\title{
Mathematical Modeling of Heavy Metal Percolation in Lube-Oil Contaminated Soil: A Case Study of Epe Automobile Mechanic Village
}

\author{
1"DUDUYEMI O., ${ }^{1}$ MORONKOLA A.A., ${ }^{2}$ ADEDEJI K.A. \\ ${ }^{1}$ Lagos State University Department of Chemical and Polymer Engineering \\ ${ }^{2}$ Lagos State University Department of Mechanical Engineering \\ *e-mail: engrduduyemi@yahoo.com \\ adetokyom@yahoo.com
}

Received: $13^{\text {th }}$ September 2019

Accepted: $23^{R D}$ June 2020

Published: $20^{\text {th }}$ September 2020

https://doi.org/10.47545/etrj.2020.5.2.059

\begin{abstract}
Indiscriminate disposal of automobile lube-oil especially around mechanic workshops was evident by the inability of plants to grow in some batches of the operation environment. The relevance of certain heavy metals and their bio-toxic effect on man and the mechanisms of their biochemical activities were investigated. A mathematical model for the transport and transformation of solute contaminant through two cases of soil columns characteristics of clay and sandy from surface to the ground water was developed and the governing equations solved numerically by orthogonal numerical technique and simulated with computer algorithm. The result shows that at a depth of 20 meter from the soil surface, the concentration decreases from about $0.075 \mathrm{~kg} / \mathrm{m}^{3}$, while it decreased to about $0.01 \mathrm{~kg} / \mathrm{m}^{3}$. At a depth of about 90 meters from the surface, the concentration of lead remained the same at about $0.01 \mathrm{~kg} / \mathrm{m}^{3}$. The major finding in the present study indicates that as time increases, the concentration of the lead increases. Also the higher the porosity of the soil the higher the concentration with time and as the depth increases, the concentration decreases. The analysis can help predict when the water table may become contaminated with leached heavy metals
\end{abstract}

Keywords Concentration, Heavymetals, Leaching, Porosity, Simulation, Transport

\section{INTRODUCTION}

The discharge of unwanted or used product into the environment, either by accidental or otherwise, is just the beginning of environmental pollution as nature had its ways of regulating herself. The effects on nature and its resources had led to a continual cycle of substitution of resources of pollutants as the major constituent. Different kinds of pollutants, each with its own toxic effects, have been natures reward for its participation in man's discovery of himself $[1,2]$. The pollutant within the medium of interest is the effect on the biotic system. In addition to physical transport process effects, complex biological and chemical transformations could also take place [3].

Heavy metals are clearly one of the biggest pollutants of land and aquatic environment especially constituents of the earth crust [4]. Human activities have drastically altered the balance and biochemical as well as geochemical cycles of some heavy metals. Therefore, the concentration of heavy metals in soils has been an issue of great interest in the past few years not only to ecologist, biologists and farmers but also environmentalist. Its persistence in soils for a very long time enters the food chain in significantly elevated amount of concerns.

The majority of solution on the contamination of soil with heavy metals comes down to the determination of their content in a few soil samples without considering the specificity of their random and systematic variation. It is important to know their sources, leaching process, chemical conversions and their mode of deposition to know their relevance to the environment. Most heavy metals have density greater than $5 \mathrm{gcm}^{-3}$, the low level of their content in soils and plants as well as the biological role of most of them makes them microelements [5, 6]. Their non-biodegradability leads to their accumulation and persistence in soils at levels that are harmful to the environment and public health $[7,8,9]$. Heavy metals are toxic for microorganisms and cannot be biodegraded 
like organic pollutants. However, they can be transformed from mobile and toxic forms into immobile and less or non-toxic forms $[10,11]$. Both adsorption and redox conditions essentially control the mobility of these chemical species in natural environments.

Recent years have seen a variety of approaches to description of water and solute movement in soils field. A number of new models have been proposed in response recently collected field data on solute leaching patterns. Many of them have been produced as the result of research into basic physics of salt, nitrogen, pesticide transport and transformation in agricultural soil. Leaches from sanitary landfills are also recognized as important ground water pollutant $[12,13]$. The contaminants are released from the refuse to the passing water by physical, chemical and microbial processes and percolate through the unsaturated environment, polluting the ground water with organic and inorganic matter.

The impact of heavy metal contamination in the vicinity of the automobile repair shops as petroleum base waste dumps has become a serious environmental and health problem and should arouse public awareness. It is therefore imperative to study the soil of auto-repair waste dumps to establish heavy metals contamination in the soil and to project their effects on the available water bodies. This study therefore seeks to determine the level of heavy metals in soil profile and underground water around automobile workshops with a view to ascertain the extent of contamination/pollution of the area.

\section{METHODS}

Two types of metals in focus were Copper and Lead which are major contaminants from machine abrasion and lube constituents next to iron were investigated and quantitatively determined on automobile repair sites in Epe automobile repair village in Epe local government, Lagos state Nigeria. The sand composition of the locations was characterized for a sandy and clay soil types data for the modeling as well as the water quality with respect to Lead and cupper respectively. The boundary conditions were set for the emerging model equations using data obtained by analysis at the soil surface concentrations and at other depths. The concentrations of the selected heavy metals were repeatedly determined after 20 and 50 days respectively to project the extent of the leachates from the surface.

\subsection{Mathematical Models}

Mathematical modeling is an accepted scientific practice providing the mechanism for comprehensively integrating basic process and describing a system beyond what can be accomplished using subjective human judgments. It is possible to construct models that better represent the natural system and to use these models in an objective manner to guide both our future research efforts and current management practices.

The modeling of contaminant transport hinges on an understanding of the mechanisms of mass release from the solid to the liquid phase and the contaminant decay. These mechanisms are influenced by such factors as climatic conditions, type of waste, site geohydrologic conditions and chemical reactions as well as microbial decomposition of organic matter [ 13, 14].

Types of mathematical model: A model is a decision tool, which if applied properly, can greatly assists decisionmaking in effectively dealing with complex issues at heavy metal deposit sites. Today, five basic categories are used Emission models, to quantify pollution emissions in the environment. These includes:

Fate models, to estimate concentrations of pollution in the environmental media; Risk models, also known as dose-response models, for the extrapolation of animal carcinogenicity data to humans and the estimation of probable human risk to cancer; Cost effectiveness models or analysis, when there's imposing alternative actions or stratifies at waste sites. In this study, information on fate models is preferred.

Water flow model: Water flow is calculated using a finite difference solution to the soil-water flow equation.

$$
\left.\frac{\delta h}{\delta t} C \theta=\frac{\delta}{\delta z} \mid K[\theta] \frac{\delta H}{\delta z}\right\rfloor-U(z, t)
$$

Where $\mathrm{h}$ is a soil water pressure head $(\mathrm{mm})$

$\theta=$ volumetric water content $\left(\mathrm{m}^{3}\right)$

$\mathrm{t}=$ time (day)

$\mathrm{H}=$ hydraulic head $(\mathrm{h}+\mathrm{z})$

$\mathrm{Z}=$ soil depth 
$\mathrm{K}=$ hydraulic conductivity $\left(\mathrm{mm}^{\mathrm{day}}{ }^{-1}\right)$

$\mathrm{C}(\theta)=\frac{\delta h}{\delta t}$ is differential water capacity and is sink term representing water lost by

Transpiration (absorption of water by plant)

Contaminant transport model: The bulk motion of the fluid, and control contaminant transport through the soil column by molecular diffusion and mechanical dispersion. Mixing due to molecular diffusion is negligible compared to that caused by dispersion. At the same time, generation of loss of mass takes place due to absorption and the biokinetics of the mass dissolved or suspended in the moving water $[15,16]$.

In general for steady-state water flow condition the transport terms.

$J_{S}=J_{D L}+J_{C L}$

$\mathrm{J}=$ total flux

$\mathrm{J}_{\mathrm{DL}}=$ is the diffusion flux in the liquid phase

$\mathrm{J}_{\mathrm{CL}}=$ is the convection flux in the liquid phase

In the case of diffusion in the liquid phase in a porous media, the equation represented by Fick's law are

$j_{D L}=D_{m}+(\theta) \frac{d C_{l}}{d z}$

$\mathrm{C}_{\mathrm{L}}=$ Concentration in the liquid phase

$\mathrm{D}_{\mathrm{m}}(\theta)=$ is the molecular diffusion coefficient

$\mathrm{D}_{\mathrm{m}}(\theta)=\mathrm{D}_{\mathrm{OL}} \mathrm{A} \exp (\mathrm{B} \theta)$

Where

$\mathrm{D}_{\mathrm{OL}}=$ Diffusion Coefficient in a pure liquid phase and $A$ and $B$ are empirical constants

The convective flux can be represented as in equation (4).

$\mathrm{J}_{\mathrm{CL}}=-\theta \mathrm{Dh}(\mathrm{q}) \frac{d \mathrm{C} 1}{d z}+\mathrm{qC}_{1}$

Where $\mathrm{q}=$ water flux

$\operatorname{Dh}(q)=$ is the hydro dynamic dispersion coefficient

Combining the molecular diffusion coefficient and hydrodynamic dispersion coefficient as

$\mathrm{D}(\theta, \mathrm{q})=\mathrm{D}_{\mathrm{M}}(\theta)+\mathrm{D}_{\mathrm{h}}(\mathrm{q})$

When $\mathrm{D}(\theta, \mathrm{q})$ is the apparent diffusion coefficient $\left(\mathrm{cm}^{-2} \mathrm{day}^{-1}\right)$.

Substituting equations $3,4,5$ into equation 2 the overall flux is obtained as in equation (6)

$J=-\theta D(\theta, q) \frac{d C_{1}}{d z}+q C_{1}$

Partitioning Contaminant between absorbed and solution phases are assumed to be nonlinear equilibrium according to Alemi et al, (1991). The process is described by equation (7).

$\mathrm{Cs}=\mathrm{Ks} \mathrm{C}^{\mathrm{n}}$

where $\mathrm{Cs}$ is the concentration of contaminant absorbed on the soil (mole $\mathrm{K}^{-1}$ ), $\mathrm{Ks}$ is the absorption coefficient $\left(\mathrm{LKg}^{-1}\right), \mathrm{C}$ is the concentration of contaminant in the soil solution.

(mole $\left.\mathrm{L}^{-1}\right), \mathrm{n}$ is the non linear equilibrium absorption reaction exponent for contaminants.

The total amount of contaminant $\left(\mathrm{C}_{\mathrm{T}}\right)$ contained in the solution and absorbed phases in a soil volume of one litre can be estimated:

$\mathrm{C}_{\mathrm{T}}=\rho C s+\theta C_{l}$

Where

$\rho$ is the soil bulk density $\left(\mathrm{gcm}^{-3}\right)$

Substituting equation (7) for Cs in equation (8) one can get the convection dispersion equation

$\mathrm{C}_{\mathrm{T}}=\mathrm{C}_{1}+(\theta+\rho \mathrm{Ks})$

Assuming the contaminant transports in the soil system occur under non steady (transient) water flow condition. The water content $(\theta)$ and water flux $(\mathrm{q})$ both vary with depth and time. Using continuity relationships of mass over space and time gives. 
$\frac{d c_{1}}{d t}=\frac{\delta j_{s}}{\delta z} \pm \emptyset$

Where $C_{\mathrm{T}}$ the total contaminant concentration is adsorbed and solution is the phase and $\Phi$ represents all sources or sinks of contaminant. Substituting equation (4) and (9) into equation (10) gives general one-dimensional transport equation for contaminant transport $[13,14]$.

$\frac{\delta c}{\delta t}(\theta+\rho K s)=\frac{\delta}{\delta z}\left[\theta D(\theta, q) \frac{\delta c}{\delta t}-q c\right] \pm \emptyset$

Where $\mathrm{C}$ is Concentration of Contaminant in soil solution $\Phi=$ possible sources or sinks term.

Equation (11) is in general form, similar equation can be written for different contaminants in soil column.

The aim of this research work was to design a mathematical model that would predict the heavy metal percolation in soil, with the case study of auto mechanic repair village (where many Mechanic workshops aggregate) in Epe, Lagos, Nigeria. The impact of heavy metal contamination on underground water due to series of human activities has become a serious environmental and health problem

\subsection{Transport Model Development}

The models are derived from the fundamental mass and momentum balance equation in transport phenomena. All assumptions made in the derivations are clearly stated. The solutions of the models in obtaining the parameters of Interest are also presented.

\section{Solute Movement in Unsaturated Zone:}

Consider the volume element of fluid in the figure above where a fluid is flowing through the element. Material balance of a component $\mathrm{A}$ into the three faces with a common corner at $\mathrm{E}$ is $\mathrm{M}_{\mathrm{A}}$.

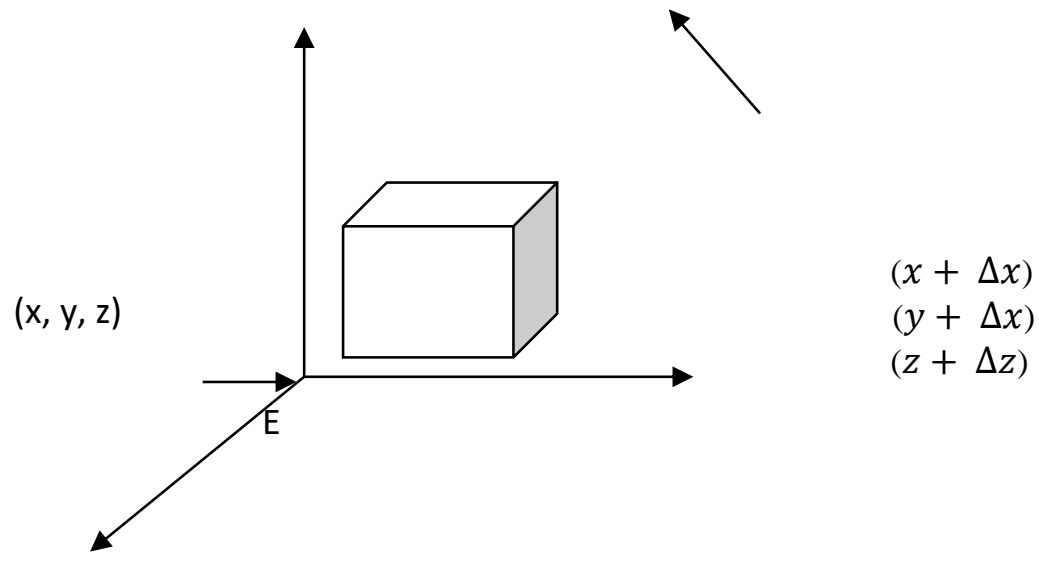

Figure 1: Elemental consideration of particulate movement in three dimensional pathways

$M_{A}\left[\left(N_{A, X}\right)_{x+\Delta x} \Delta \mathrm{y} \Delta \mathrm{z}+\left(N_{A, y}\right)_{y+\Delta y} \Delta \mathrm{x} \Delta \mathrm{z}+\left(N_{A, z}\right)_{z+\Delta z} \Delta \mathrm{x} \Delta \mathrm{y}\right]$

Where $N_{A, X}$ signifies the $\mathrm{x}$-directed flux and $\left[\left(N_{A, X}\right) \mathrm{x}\right.$ its value at location $\mathrm{x}$.

Similarly, the mass rate of flow out of the three faces with a common corner at $\mathrm{G}$ is

$M_{A}\left[\left(N_{A, X}\right)_{X} \Delta_{x} \Delta_{y} \Delta_{z}+\left(N_{A, y}\right)_{Y} \Delta_{y} \Delta_{x} \Delta_{z}+\left(N_{A, z}\right)_{Z} \Delta_{z} \Delta_{x} \Delta_{y}\right]$

Note:

The total component $\mathrm{A}$ in the element is $\in \Delta_{X} \Delta_{Y} \Delta_{Z} \ell_{A}$

And its rate of accumulation is therefore is $\Delta_{x} \Delta_{y} \Delta_{z} \in \frac{\partial \ell_{A}}{\partial \theta}$

Note

$$
\begin{aligned}
& \ell=\ell_{\mathrm{A}}+\ell_{\mathrm{B}} \\
& \mathrm{q}=\mathrm{q}_{\mathrm{A}}+\mathrm{q}_{\mathrm{B}} \\
& \mathrm{N}_{\mathrm{A}}=\mathrm{N}_{X_{A}}+\mathrm{J}_{\mathrm{A}}
\end{aligned}
$$


Where $U_{X}$ is the mass - average velocity such that

$\ell U_{X}=U_{A X} \ell_{\mathrm{A}}+U_{B X} \ell_{\mathrm{B}} \quad=M_{A} N_{A X}+M_{B} N_{B X}$

Therefore for component balance; $\frac{\partial\left(M_{A} N_{A X}+M_{B} N_{B X}\right)}{\partial x}=\frac{\ell \partial u_{x}}{\partial x}+\frac{U_{x} \partial \ell}{\partial x}$

Considering the three directions, equation 15 becomes;

$\ell\left(\frac{\partial \mathrm{Ux}}{\partial \mathrm{x}}+\frac{\partial \mathrm{Uy}}{\partial \mathrm{y}}+\frac{\partial \mathrm{Uz}}{\partial \mathrm{z}}\right)+U_{x} \frac{\partial \ell}{\partial \mathrm{x}}+U_{y} \frac{\partial \ell}{\partial \mathrm{y}}+U_{z} \frac{\partial \ell}{\partial \mathrm{z}}+\in \frac{\partial \ell}{\partial \theta}+(1-\epsilon) \frac{\partial \mathrm{q}}{\partial \mathrm{t}}$

This is the equation of continuity or a mass balance for total substance. If the density is constant, it becomes

$\frac{\partial U_{x}}{\partial x}+\frac{\partial U_{y}}{\partial y}+\frac{\partial U_{z}}{\partial z}=0$

Considering material balance for component $\mathrm{A}$ in equation 13

$M_{A} N_{A X}=U_{x} \ell_{A}+M_{A} J_{A X}$

$U_{x} \in \ell_{A}+M_{A} \in J_{A X}=\in\left(U_{x} \ell_{A}+M_{A} J_{A X}\right)$

Equation 18 is the equation of continuity for substance A. Assuming a solution of constant density, combine equations 16 and equation 12 gives:

$\in\left(\left[\mathrm{U}_{\mathrm{x}} \frac{\partial \mathrm{C}_{\mathrm{A}}}{\partial \mathrm{x}}+\mathrm{U}_{\mathrm{y}} \frac{\partial \mathrm{C}_{\mathrm{A}}}{\partial \mathrm{y}}+\mathrm{U}_{\mathrm{z}} \frac{\partial \mathrm{C}_{\mathrm{A}}}{\partial \mathrm{z}}\right]-\in \mathrm{D}_{\mathrm{AB}}\left[\frac{\partial^{2} \mathrm{C}_{\mathrm{A}}}{\partial \mathrm{x}^{2}}+\frac{\partial^{2} \mathrm{C}_{\mathrm{A}}}{\partial \mathrm{y}^{2}}+\frac{\partial^{2} \mathrm{C}_{\mathrm{A}}}{\partial \mathrm{z}^{2}}\right]+\in \frac{\partial \mathrm{C}_{\mathrm{A}}}{\partial \theta}+(1-\epsilon) \frac{\partial \mathrm{q}_{\mathrm{A}}}{\partial \mathrm{t}}=\mathrm{R}_{\mathrm{A}} \in\right)$

Re-arranging equation (20)

$\in\left(\left[U_{x} \frac{\partial \mathrm{C}_{A}}{\partial x}+U_{y} \frac{\partial \mathrm{C}_{A}}{\partial y}+U_{z} \frac{\partial \mathrm{C}_{A}}{\partial z}\right]+\in \frac{\partial \mathrm{C}_{A}}{\partial \theta}+(1-\epsilon) \frac{\partial q_{A}}{\partial \mathrm{t}}=\in D_{A B}\left[\frac{\partial^{2} C_{A}}{\partial x^{2}}+\frac{\partial^{2} C_{A}}{\partial y^{2}}+\frac{\partial^{2} C_{A}}{\partial z^{2}}\right]+R_{A} \in\right)$

Note: Since the reaction increases, the concentration of the substance decreases, the sign of $\mathrm{R}_{\mathrm{A}}$ changes to negative $(-)$.

$$
\in \frac{\partial \mathrm{C}_{A}}{\partial \theta}=\in D_{A B}\left[\frac{\partial^{2} C_{A}}{\partial z^{2}}\right]-\in U_{z} \frac{\partial \mathrm{C}_{A}}{\partial z}-(1-\epsilon) \frac{\partial q_{A}}{\partial \mathrm{t}}+R_{A} \in
$$

Divide all through by $\in$

$$
\frac{\partial \mathrm{C}_{A}}{\partial \theta}=D_{A B}\left[\frac{\partial^{2} C_{A}}{\partial z^{2}}\right]-U_{z} \frac{\partial \mathrm{C}_{A}}{\partial z}-\frac{(1-\epsilon)}{\epsilon} \frac{\partial q_{A}}{\partial \mathrm{t}}+R_{A}
$$

Equation 23 is governing the transport or movement of metal in the soil considering the following factors

a. Porous medium is homogenous

b. Adsorption on the soil surface

c. Metal degradation by micro-organisms

Since

$\frac{\partial q}{\partial t}=K_{F} \frac{\partial \mathrm{C}_{A}}{\partial \theta} \quad$ and $\quad R_{A}=\frac{\mu_{m} x c_{A}}{Y\left(K+C_{A}\right)}$

Where

$$
\left[1+\frac{(1-\epsilon)}{\epsilon} K_{F}\right] \frac{\partial \mathrm{C}_{A}}{\partial \theta}=D_{A B}\left[\frac{\partial^{2} C_{A}}{\partial z^{2}}\right]-U_{z} \frac{\partial \mathrm{C}_{A}}{\partial z}-\frac{\mu_{m} x c_{A}}{Y\left(K+C_{A}\right)}
$$

$\epsilon=$ porosity of soil

$\mathrm{K}_{\mathrm{F}}=$ partition coefficient

$\mathrm{C}_{\mathrm{A}}=$ Concentration of metal

$\mathrm{D}_{\mathrm{AB}}=$ Dispersion coefficient of metal 
$\mathrm{U}_{\mathrm{z}}=$ Velocity of solution of metal in $\mathrm{z}$-direction

$\Sigma \mu_{m}=$ Summation of maximum specific growth rate $\left(\mathrm{hr}^{-1}\right)$

$\mathrm{K}=$ half saturation constant

$\mathrm{Y}=$ Yield i.e (ratio of the amount of biomass formed to the amount of metal consumed per unit vol.)

$\mathrm{X}=$ concentration of biomass (mg cell dry weight/L)

$\mathrm{z}=$ vertical co-ordinate direction, take positive downward

The values of the parameters used for the numerical evaluations were obtained $[13,15]$. Subject to the outlined boundary conditions and solved using orthogonal collocation with computer simulation.

\section{Initial and boundary conditions:}

Initial condition

$\mathrm{C}=0 \quad$ at $\mathrm{t}=0$

Where $\mathrm{C}=$ Concentration of substance

$\mathrm{t}=$ time

$\mathrm{z}=$ vertical distance covered

$\mathrm{h}=$ total height of the medium environment

Boundary conditions

$\begin{array}{llc}\text { At } \quad \mathrm{t}=0 & \frac{\partial c}{\partial z}=0 & \mathrm{t}=0 \\ & \mathrm{z}=0 & \mathrm{z}=\mathrm{h}\end{array}$

\section{RESULTS AND DISCUSSION}

The results of simulation of the model equation based on the boundary conditions using orthogonal numerical technique at interval of collocation points is plotted in Figure 1. It is observed that as the depth increased, the concentration of the metal's decreases. This implies that as the depth of the soil increases the concentration of the heavy metals is reduce drastically and the major concentrations would be at the upper sub-soils. The time accumulation of the heavy metals is consequential of devastating growth characteristic of plants found in these regions and at times total dislodgment of some plant species may be inevitable. Since more of the metals abounds at the top sub-soil, the washing of the metals into major water bodies is also possible by rain, wind and erosion. However, the water obtained from wells and boreholes would be below the threshold value until a very long time of leaching and percolation and so the water will be safe for consumption.

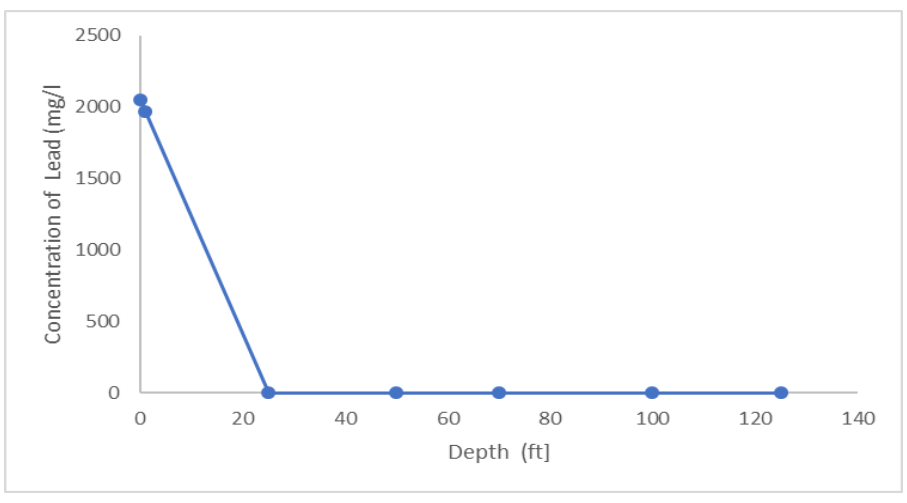

Fig 1: Simulated concentration profiles of heavy metals for a one directional evaluation

The effects of soil types on the heavy metal's percolation was also investigated for two types of soil viz-a-viz Sandy and clay soil characterized by their porosities designated by $\mathrm{Y}_{1}$ for sand (porosity 0.49 ) and $\mathrm{Y}_{2}$ for clay (porosity 0.35 ). The effect of this differential in porosity is shown in Figure 2. It is evident that the clay soil pattern retains more metals than the sand by the gradient of the two plots.[15] reported the rate of movement of aqueous lead in clay and sand oil to be $0.0015 \mathrm{~m} / \mathrm{hr}$ and $0.005 \mathrm{~m} / \mathrm{hr}$ respectively. This retention in clay may be adduced to the fine particles of the soil and the power of adsorption by capillarity. 


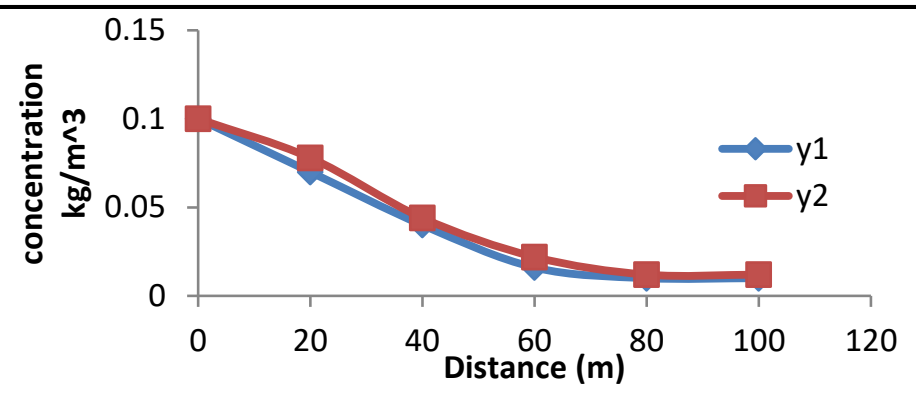

Fig 2: Effect of Porosity on concentration Profile of heavy metals in Sand $\left(\mathrm{y}_{1}\right)$ and Clay soil $\left(\mathrm{y}_{2}\right)$

The concentration profile of heavy metals with reference to time as simulated showed a relatively linear relationships but with differing gradient from the soil type and depth dependent profiles of the heavy metals. This effect is shown Figure 3.

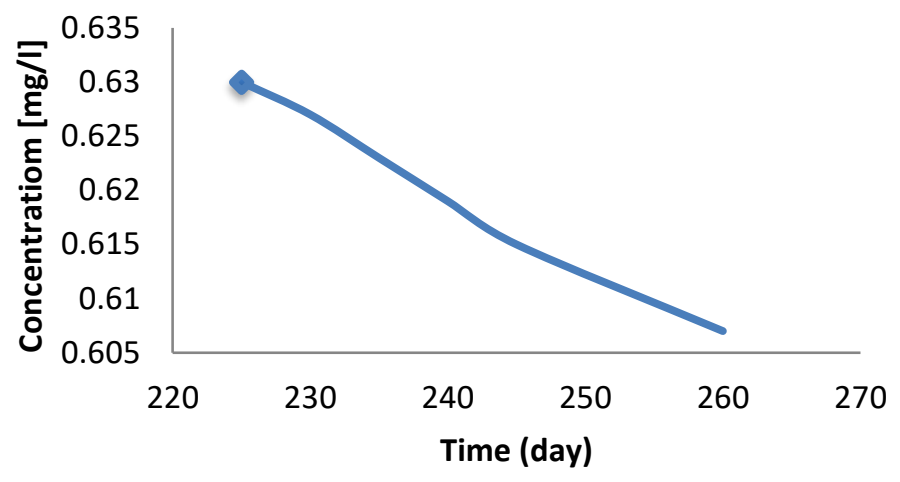

Fig 3.: Effect of time on concentration profile of Heavy metals percolation.

In a system chosen for heavy metal transport simulation, a 1000metre hypothetical soil Column with one directional flow in vertical direction was simulated. The soil diffusion coefficient of $0.1 \mathrm{~m}^{3} / \mathrm{hr}$ and partition coefficient of $50 \times 10^{3} \mathrm{~m}^{3} / \mathrm{kg}$ were considered for the 50 days appraisals. The concentrations Profile decreases with increase in distance, ten days later, it returned to a steady state [15].

The simulated results indicated concentration of heavy metal obtained decreases but at a very small rate such that in 35 days, about $0.025 \mathrm{mg} /$ day was estimated as shown in the Figure 4;

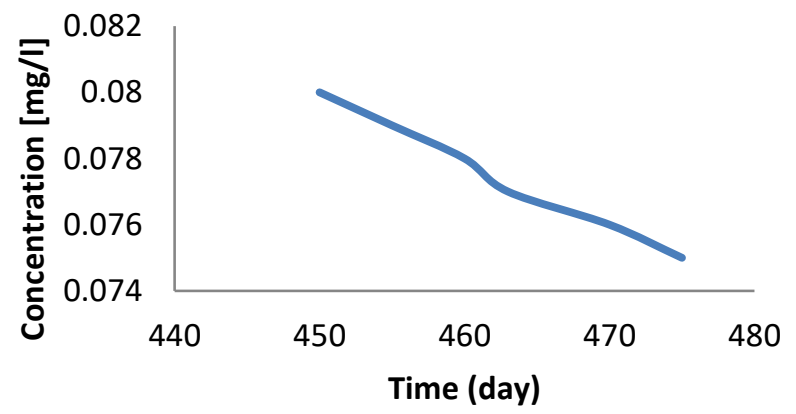

Fig 4. Effect of depth on concentration profile of in an hypothetical soil sample

It is observed that as the depth increases, the concentration of the metal's decreases. This implies that if the depth of the well and the borehole are increased, the concentration of the heavy metals will reduce far below their threshold such that the water will be safe for consumption.

\section{CONCLUSION}

A mathematical model that described heavy metal percolation in both clay and sandy soils with microbial biomass have been developed. The results of simulation shows the influences of both adsorption processes related to heavy 
metal transport and level of unsaturation in the soil. The model would be a useful tool for the estimation of heavy metal content of leachates from wastes. The model can be used for the prediction of water pollution in groundwater system.

\section{REFERENCES}

[1] Lacatusu, R. (1998). Appraising levels of soil contamination and pollution with heavy metals: Developments for planning and sustainable use of land resources. European Soil Bureau joint research center, 393-402.

[2] Peplow, D. (1999). Environmental Impact of Mining in Eastern Washington, Center for water and watershed studies fact sheet, university of Washington, seattle.

[3] Komisarek, J. (1997) Spatial variability of content and accumulation of mobilisable form of $\mathrm{Cu}, \mathrm{Zn}, \mathrm{Mn}, \mathrm{Fe}$ and $\mathrm{Pb}$ in soil of koscian plain .ROCZ .AR Pozn 21,294.

[4] Hakan, P. (2006). The distribution and sources of heavy metals in Izmit Bay surface sediment affected by polluted stream. Marine Pollution Bulletin.

[5] Ogwuegbu, M.O., and Ijioma, M.A. (2003) Effects of Heavy Certain Metals in the Population due to Mineral Exploitation.

[6] Lacatusu, R. (1998). Appraising levels of soil contamination and pollution with heavy metals: Developments for planning and sustainable use of land resources. European Soil Bureau joint research center, 393-402

[7] Ewing, R.E., and Lin, T. (1991). Class of parameter estimation techniques for fluid flow in porous media, Advances in water resources, 24: No . 2, p89-97.

[8] Lacatusu, R. (1998). Appraising levels of soil contamination and pollution with heavy metals: Developments for planning and sustainable use of land resources. European Soil Bureau joint research center, 393-402.

[9] Fang, T. H. \& Hong, E. (1999). Mechanisms influencing the spacial distribution of trace metals in surficial sediments off the south- western Taiwan. Marine Bulletin, 38, 1026-1037

[10] Kabata-Pendias, A., and Pendias, H. (1999). Biogeochemistry of trace elements, (in Polish) PWW Warszawa , pp 397.

[11] Udedi, S.S. (2003) From Guinea Worm scourge to Metal Toxicity in Ebonyi State, Chemistry in Nigeria as the New Millennium Unfolds

[12] Robert, E. TReybal, Mass- Transfer Operation Mcgrawhill Books, International Edition Singapore 1980

[13] Stroud, K.A. Advanced Engineering mathematics. Fifth Edition, CPR Press

[14] United Nation Environmental Protection/Global Program of Action (2004). Why the marine environmental needs protection from Heavy Metals, Heavy Metals 2004

[15] Beyenal H, Lewandowski, Z B, and Gary Harkin (2004). Biofilm Structure: Facts and Fiction. Biofouling, Taylor and Francis VOL $20(1)$, pp $1-2$.

[16] Nedunuri, K. V.; Erickson, L. E.; and Govindaraju, R. S. (1998) "Modelling the Role of Active Biomass on the Fate and Transport of a Heavy Metal in the Presence of Root Exudates," Journal of Hazardous Substance Research: Vol. 1. https://doi.org/10.4148/1090-7025.1009 